\title{
Mediation in a Socio-Cognitive Approach to Writing for Elementary Students: Instructional Scaffolding
}

\author{
Chiew Hong $\mathrm{Ng}$ * (iD) and Yin Ling Cheung \\ English Language and Literature Academic Group, National Institute of Education, \\ Nanyang Technological University, Singapore 637616, Singapore; yinling.cheung@nie.edu.sg \\ * Correspondence: chiewhong.ng@nie.edu.sg; Tel.: +65-679-035-86
}

Received: 7 May 2018; Accepted: 19 June 2018; Published: 22 June 2018

\begin{abstract}
This research investigates how elementary teachers mediate the learning of writing through a socio-cognitive approach. The study reveals how in effective instructions for writing development, teachers can build narrative knowledge in a socio-cognitive approach through these types of instructional scaffolding: explicit outcomes and expectations, modelling, bridging, contextualizing, schema building, re-presenting text and developing metacognition. The study also illustrates through examples, the use of the instructional scaffolding functions by two teachers mediating between students' current knowledge levels in writing in English and the requisite expert understandings of the narrative genre in actual classroom practice. The adapted instructional scaffolding functions proposed in this article enrich the field of learning and teaching of writing by providing a means for teachers to mediate the learning of writing. The study also highlights the value of qualitative interpretive approaches in contributing to the domain of pedagogical approaches in writing for elementary students.
\end{abstract}

Keywords: mediation; socio-cognitive approach; writing; elementary students; instructional scaffolding

\section{Introduction}

This article focuses specifically on the socio-cognitive approach to writing for the narrative genre for 9- and 10-year old students from mainstream classes to explore in particular how teachers' mediation in the class facilitates the learning of writing. As the present study adopts the socio-cognitive approach to writing, this approach is defined to contextualize the teaching of the genre of narrative to elementary students. Next, this paper talks about how mediation in writing could be effected through the socio-cognitive approach to writing and instructional scaffolding. Then, this paper details the adapted instructional scaffolding functions (adapted from Walqui [1] and used in Simeon's [2] study) for mediating writing. The findings demonstrate how learning to write narratives using the socio-cognitive approach can be facilitated through the use of the instructional scaffolding functions by looking at patterns across 21 English language writing lessons and examples drawn from two teachers in actual classroom practice.

\subsection{Defining the Socio-Cognitive Approach to Writing}

The socio-cognitive approach to writing looks at writing in terms of social and cognitive processes or strategies. Studies exploring writing from the social perspective have integrated the notion of genre which refers to "abstract, socially recognised ways of using language" [3] (p. 149) characterised as broad rhetorical patterns such as narratives, recounts, arguments, and expositions or what Martin [4] has termed elemental genres.

Studies looking at cognitive processes or strategies for writing have highlighted these aspects: (a) planning (generating ideas, organizing, and goal-setting); (b) translating (putting thoughts and 
ideas from plans into sentences); and (c) reviewing (reading and editing) [5]. These cognitive processes are under the control of meta-cognitive processes which relate to the ability to control and monitor the use of cognitive strategies for writing. Raphael, Englert, and Kirschner [6] have suggested three types of metacognitive knowledge for writing: (a) Declarative knowledge about task structure and task goals and steps for writing which can be developed through pre-writing activities, drafting, revising, and copy-editing; (b) procedural knowledge about the implementation of various actions or strategies i.e., deciding which strategy to use from a repertoire of behavior available when composing to achieve a particular goal; and (c) conditional knowledge about the conditions for selecting a particular strategy or when and why to use strategies during the writing process.

\subsection{Mediation through Scaffolding in Socio-Cognitive Writing Instruction}

Mediation in writing instruction through the use of scaffolding in L2 writing instruction has been the focus of research [7,8]. In writing, scaffolding is a highly flexible and adoptable model of instruction supporting students' acquisition of both basic skills and higher order processes in explicit instructions within authentic writing contexts and enabling teachers to differentiate instructions for a diverse range of students [9].

In scaffolding writing through the cognitive approach, novices are provided with cognitive tools and strategies to scaffold writing performance and are reminded of the procedural steps, perspectives, tools, or higher order strategies that they may self-employ to plan, monitor, or revise their texts [10].

Mediating writing through the genre approach means explicit scaffolding of skills by teachers for every stage of the composing process [11] as the theoretical underpinning of the genre approach is Vygotsky's [12] notion of interactive collaboration where the teacher takes on the authoritative role to scaffold or support learners in achieving their potential level of performance [13]. This is effected through the teaching-learning process or cycle (based on Halliday's [14] Systemic Functional Linguistics approach) of (a) modelling; (b) joint negotiation (also termed joint construction); and (c) independent construction [13].

\subsection{Mediating Learning to Write: Instructional Scaffolding and the Socio-Cognitive Approach}

Mediation in learning to write can be realised through instructional scaffolding which was first used to describe temporary dynamic support provided by parents and teachers to toddlers learning to construct pyramids with wooden blocks [15]. Instructional scaffolding is meant to extend or fill in gaps in students' current abilities and knowledge to enable them to complete tasks [16] through both simplifying non-essential elements and drawing students' attention to important complex task elements for robust learning [17]. Teachers need to keep students interested or engaged in the learning task [18] and enable students to understand how to perform a task successfully [15]. Teachers also need to take account of goals which can influence how learners interpret and use scaffolds [19].

When Woods et al. [15] originally proposed instructional scaffolding, there was no link to any particular theory as the grounded theory approach [20] was adopted. However, their observation that scaffolding support was built on toddlers' existing skills and knowledge points to how in instructional scaffolding, in terms of cognition, teachers can tap on students' existing knowledge, extend the knowledge by showing students how to use the knowledge in new ways or for more complex tasks and point out the critical factors students should attend to [16].

Mediating through scaffolding in writing typically includes modelling and discussion of texts, explicit instruction, and teacher input which can be realised through the genre teaching-learning process or cycle-modelling, joint construction, and independent construction [13]. The modelling stage (termed deconstruction) consists of building the field and modelling the genre. Firstly, in building the field, the teacher would ask students to share what they already know about the topic (prior knowledge or schema activation) or provide additional resources about the topic [21]. In modelling, the teacher provides a model text type and analyzes the text in terms of text structure, its linguistic features and the communicative purpose to develop "learners' conscious knowledge of language and 
how language works" [22] (p. 48). This is a contextualizing step to develop students' awareness that a text is influenced by its purpose, the writer's role, the anticipated audience, as well as provide the context for building shared knowledge of a target genre [23]. Secondly, in the joint construction stage, students are guided and helped by the teacher to reconstruct the genre being taught and the students may revise and paraphrase the vocabulary usage, the grammatical patterns, and textual devices before embarking on independent writing in the final stage. In Hyland's [13] view, scaffolding will be most evident at the early stages of learning a genre where the teacher intervenes at this stage to model and discuss texts, deconstruct and analyse their language and structure.

\subsection{Proposed Model of Instructional Scaffolding for the Socio-Cognitive Approach to Writing}

In our study, to examine how the socio-cognitive approach to writing could be implemented in actual classroom application, we used the adapted instructional scaffolding functions to analyse the mediation process such as how teachers tap on/extend students' existing knowledge or teach students what to attend to [16]. The functions are based mainly on Walqui's [1] instructional scaffolding framework which Simeon [2] has used to look at the intention and work of the teacher's discourse in teaching writing chiefly in terms of (1) bridging: "sharing personal experiences" and "activating students' prior knowledge"; and (2) modeling. To have a comprehensive picture of the types of instructional scaffolding functions in mediating writing, the present study has used Walqui's [1] six main types of instructional scaffolding:

1. Modeling: Giving students clear examples of what is requested of them for imitation to complete the writing task and the teacher models "appropriate language use for the performance of specific academic functions" (p. 170). This can be done as a class activity first.

2. Bridging: Helping students to activate prior knowledge or establish a personal link between students and the subject matter, such as asking students to share personal experiences related to the theme.

3. Contextualising: Making academic language accessible and engaging for students through using authentic objects, sources of information, realia or analogies based on students' experiences.

4. Schema Building: Activating students' schema and weaving new information into pre-existing structures of meaning to enable them to accept new connections and to organize knowledge and understanding. Giving general knowledge or the broad picture before studying the details.

5. Re-presenting Text: Asking students to transform the linguistic constructions of one genre into another genre.

6. Developing Metacognition: Helping students manage their thinking in terms of strategy application, strategy choice, monitoring, evaluating and adjusting performance during activity; and planning for future writing based on evaluation of performance.

The study has also adopted two of Hyland's [3] principles of writing instruction-(1) Contextualising where writing is "a social activity ... supported within familiar routines, or cycles of activity, and by linking new contexts and understandings to what students already know about writing" (p. 152) and (2) Stating outcomes and expectations-where "teachers are explicit about what is being studied, why it is being studied, and what will be expected of students" (p. 152) —as part of the instructional scaffolding functions. This is because goals can influence how learners interpret and use scaffolds in instructional scaffolding [19] and both Woods et al. [15] and Hattie [24] have highlighted teachers' need to clarify learning intentions and success criteria for students in teaching writing as part of instructional scaffolding.

Walqui's [1] framework is useful for our study as the mediation of the socio aspect is enacted through the genre approach in terms of modelling, bridging, contextualizing, schema building and re-presenting text. The cognitive aspect of the socio-cognitive approach through the framework looks at (a) developing metacognition where instructors teach for metacognition so students ... learn to regulate their cognitive activities in terms of knowing what the writing strategies are; how to use the 
strategies; when, where and why to apply the strategies and how to evaluate the use of the strategies $[6,25]$ and (b) the cognitive processes or strategies for writing such as planning: generating ideas, organizing, and goal-setting [26].

\section{Methodology}

\subsection{Research Focus}

The focus of the study is on the use of the adapted instructional scaffolding functions in a socio-cognitive approach to mediate writing of narrative writing skills. The study firstly looks broadly at teachers' use of adapted instructional scaffolding functions to mediate learning to write narrative (21 lessons). The study next looks at descriptive data in terms of examples in the use of the instructional scaffolding functions through looking at two teachers' lessons based on the teaching-learning cycle of modelling and joint construction.

\subsection{Context}

The data were taken from the second phase of the larger study focusing on how elementary English language Singaporean teachers teach writing in traditional writing classes in contrast to teaching based on a socio-cognitive approach to writing; it involved three classes of 9- and 10-year-olds in their fourth year of schooling in a Singaporean school. The school was a neighborhood primary school. Students used different mother tongues, such as English, Malay, Chinese, Hindi, and Cantonese at home. There was a total of 97 children considered for intervention in the study in 2017, as these students still experienced difficulties understanding and writing the narrative genre. The experienced English Language class teachers (minimum 5 years of teaching) were trained by the principal investigator of the project to carry out the research intervention.

A brief description of teacher training is as follows: The teachers were taught how to explicitly teach the thinking processes involved in enacting genre practices for the planning, organizing and revising stages according to the macro rhetorical goal (i.e., to entertain the readers, or to make readers admire the characters) of the narrative genre. At the planning stage, teachers should think about the rhetorical situation (i.e., purpose, audience, and context of writing) and their macro rhetorical goal. They should think about their goal with respect to the reader effect and the writer role. They should consider what information would best fit the rhetorical situation and the macro rhetorical goal. At the organizing stage, teachers should decide what ordering and structuring of the information would best help them achieve their rhetorical goal. They should make sure that the organization structure fits the rhetorical situation. They should be aware of the reader's expectations, and they should anticipate what the reader would like to know in their compositions. At the writing/revising stage, teachers should refer to the macro rhetorical goal and anticipate the reader's expectation in choosing words, sentences, and styles of expression. They should choose words and expressions that suit the rhetorical goal.

After the teacher training, the teachers planned the lessons on the basis of the socio-cognitive approach to writing and then taught using language accessible to these students and gave them feedback on their efforts in using the writing scaffold. The students were taught moves to fit each rhetorical situation such as the ordering of information or the sequencing of events.

\subsection{Data Collection Procedure}

There were class observations (totaling 21 lessons) over a 12-month period. All videos were subsequently transcribed. Field notes of the observations were used to describe the class and contextualize the lessons based on the observations. 


\subsection{Analytical Framework}

To analyse the lessons for the mediation process for the socio-cognitive approach to writing, the study uses two of Hyland's [3] principles of writing instruction and Walqui's [1] instructional scaffolding framework (see Table 1).

Table 1. Instructional scaffolding functions.

\begin{tabular}{|c|}
\hline Instructional Scaffolding Functions \\
\hline $\begin{array}{l}\text { Explicit outcomes and expectations [3]: State what is being studied, why it is being studied, and what will be } \\
\text { expected of students. }\end{array}$ \\
\hline Modeling [1]: Provide examples of expected writing. \\
\hline $\begin{array}{l}\text { Bridging [1]: Personal link e.g., share personal experiences or activate prior knowledge (linking new contexts } \\
\text { and understandings to what students already know about writing [3]). }\end{array}$ \\
\hline $\begin{array}{l}\text { Contextualising [1]: Make academic language accessible and engaging for students through using authentic } \\
\text { objects, sources of information, realia or analogies based on students' experiences. }\end{array}$ \\
\hline $\begin{array}{l}\text { Schema Building [1]: Activate students' schema, weave new information into pre-existing structures of meaning, } \\
\text { give general knowledge or the broad picture before details. }\end{array}$ \\
\hline Re-presenting Text [1]: Transform one genre into another. \\
\hline $\begin{array}{l}\text { Developing Metacognition [1]: Thinking about strategy application/choice, monitoring, evaluating, planning for } \\
\text { future writing. }\end{array}$ \\
\hline
\end{tabular}

\subsection{Data Analysis}

There were two stages in the data analysis. For stage 1, all the lessons from the data set of 21 lessons were analysed initially by the first author for the presence of instructional scaffolding functions for the socio-cognitive approach in writing, and then with the second author counterchecking the analysis. The function was counted as present in the lesson as long as there was one occurrence/use. There were lessons where most of the teachers had not used the specific scaffolding function (e.g., re-presenting text). After each lesson was analysed for the presence/absence of all the instructional scaffolding functions, each instructional scaffolding function was calculated across the 21 lessons as a percentage to get an overview of the occurrence/usage of each instructional scaffolding function for all the lessons (see Table 2).

Table 2. Summary of the occurrence/use of instructional scaffolding functions for 21 lessons.

\begin{tabular}{cc}
\hline Instructional Scaffolding Functions & Occurrence of Function $(\boldsymbol{n}=\mathbf{2 1}$ Lessons $)$ \\
\hline Explicit outcomes and expectations & $95 \%$ \\
Modeling & $76 \%$ \\
Bridging & $57 \%$ \\
Contextualising & $100 \%$ \\
Schema Building & $76 \%$ \\
Re-presenting Text & $8 \%$ \\
Developing Metacognition & $61 \%$ \\
\hline
\end{tabular}

For stage 2, as part of descriptive data, two teachers' lessons were analysed in detail for the use of the instructional scaffolding functions and examples from two teachers were used to illustrate the functions in actual classroom practice, as well as to compare and contrast the use by the two teachers in mediating writing. After discussing and looking through the 21 lessons, these two teachers were selected because both teachers could effectively engage the students and promote collaborative learning through effective questioning techniques or the use of diverse activities. 


\section{Findings}

The findings of the study will be presented in terms of (a) an overview of the use of the instructional scaffolding functions (21 lessons); and (b) descriptive data from two lessons as illustrations of the use by teachers in actual practice.

(a) An overview of the use of the instructional scaffolding functions (21 lessons)

Table 2 shows the occurrences of the instructional scaffolding functions in 21 lessons as a form of overview. In $95 \%$ of the lessons, outcomes and expectations of the lessons were stated explicitly when teachers told the students the learning objectives pertaining to writing at the start of the lesson or at the start of each specific activity, so that students knew what to expect for the lesson as a whole or at different stages of the lesson (see Section 3.1 for specific illustrations). That most teachers did so was not surprising because the teachers were trained to think about the rhetorical situation (i.e., purpose, audience, and context of writing) and their macro rhetorical goal (see Section 2.2 for explanation of teacher training) in the planning stage i.e., they had to explain to students what was being studied, why it was being studied and what would be expected of them [3]. Since the teachers were using the socio-cognitive approach to writing, in $76 \%$ of the lessons, examples of expected writing was provided as scaffolding. All the teachers used teaching material such as activity sheets, Power Point slides, videos, sample narratives, or analogies based on students' experiences to contextualise the learning of narrative. Because the focus was on narrative, it was not surprising that there was minimal re-presenting of text $(8 \%)$. Teachers were engaged in schema building in $76 \%$ of the lessons but sharing of personal experiences or activating prior knowledge occurred in only $57 \%$ of the lessons. In $61 \%$ of the lessons, teachers encouraged some form of metacognitive thinking about writing narratives.

(b) Descriptive data from two lessons as illustrations of the use by teachers in actual practice

In this part, we present the findings in terms of descriptive data to show how teachers mediate the learning of writing through the socio-cognitive approach in actual practice. The findings are presented in terms of exemplars for each instructional scaffolding functions in two lessons.

When implementing the socio-cognitive approach to writing, in terms of lesson structuring, Teacher A went through modelling in the deconstruction stage of the genre approach by getting students to do story mapping for the stages of Character, Setting, Event, Problem, Solution, and Ending as a class, before constructing a story map for a parallel story through group planning. Teacher B was engaged in getting students to create a story about a positive or happy or surprising experience using Rory Cubes, and applying a "Do, say, think and feel" sentence that was taught in the previous writing lesson before completing individual quick writing for the planning stage of writing. The teacher also taught the concept of feelings being linked to something tangible or intangible.

\subsection{Explicit Outcomes and Expectations}

In mediating writing through instructional scaffolding, teachers need to clarify learning intentions and success criteria for students in teaching writing $[15,24]$. The two teachers in this study stated explicitly the lesson outcomes and their expectations (congruent with the socio-cognitive approach to writing) at the beginning or throughout the lesson to raise students' awareness of what was being studied, why it was being studied, and what would be expected of them [3]. While Teacher A reiterated the same outcome and expectation four times throughout the lesson as reinforcement (see Learning Outcomes Examples 1A, 2A, 3A and 4A in Table 3), Teacher B stated different outcomes and expectations for each activity as Teacher $B$ had various activities with different outcomes (see Learning Outcomes Examples 1A, 1B, 1C, 1D and 1E). Still, both teachers' expectations were in terms of what students had to do to demonstrate their learning. 
Table 3. Explicit outcomes and expectations.

\begin{tabular}{|c|c|c|}
\hline $\begin{array}{l}\text { Instructional } \\
\text { Scaffolding } \\
\text { Functions }\end{array}$ & Teacher A & Teacher B \\
\hline \multirow{9}{*}{$\begin{array}{l}\text { Explicit } \\
\text { outcomes and } \\
\text { expectations }\end{array}$} & Learning Outcome Example 1A & Learning Outcome Example 1B \\
\hline & \multirow{2}{*}{$\begin{array}{l}\text { Tr: For today's lesson, you are required to construct your } \\
\text { own story map ... of your own parallel fairy tale ... we } \\
\text { are going to go through a quick identification of the story } \\
\text { map behind this ... story. } \\
\text { SS: (listening) } \\
\text { Learning Outcome Example 2A (Reiteration } 1 \text { ) }\end{array}$} & $\begin{array}{l}\text { Tr: We gonna do some continuous writing. } \\
\text { Ss: Yes (Chorus) } \\
\text { Learning Outcome Example 2B }\end{array}$ \\
\hline & & \multirow{3}{*}{$\begin{array}{l}\text { Tr: Can you try to create a story ... with one of these } \\
\text { themes over here ... about "a positive or a happy } \\
\text { experience" or, you can do something about "a } \\
\text { surprise" ok? You can do it with both. } \\
\text { Ss: Yes (Chorus) } \\
\text { Learning Outcome Example 3B }\end{array}$} \\
\hline & $\begin{array}{l}\text { Tr: Now the objective for today's ... again. You are to } \\
\text { construct your own ... story map, right? }\end{array}$ & \\
\hline & SS: (listening) & \\
\hline & Learning Outcome Example 3A (Reiteration 2) & Tr: Our theme for the day is "a pleasant surprise". \\
\hline & \multirow{2}{*}{$\begin{array}{l}\text { Tr: Again ... (watching today's objective) you are ... to } \\
\text { construct ... a story map ... on your own ... parallel to } \\
\text { what you have just ... read (pointing to the story } \\
\text { elements that they did on the board) the characters, } \\
\text { the setting, the event, problem, solution and ending. } \\
\text { SS: Yes (choral) } \\
\text { Learning Outcome Example } 4 \text { A (Reiteration } 3 \text { ) }\end{array}$} & $\begin{array}{l}\text { This is what we gonna write today. Ok? } \\
\text { SS: (Listening attentively) } \\
\text { Learning Outcome Example 4B }\end{array}$ \\
\hline & & $\begin{array}{l}\text { Tr: We gonna write the "Topic Blast" Do you remember } \\
\text { the topic blast? } \\
\text { Ss: Yes (Chorus) } \\
\text { Learning Outcome Example 5B (Quick Writing) }\end{array}$ \\
\hline & $\begin{array}{l}\text { Tr: The lesson objective of today is for you to create your } \\
\text { own story map .... parallel to the once given, right? } \\
\text { SS: Yes (choral) }\end{array}$ & $\begin{array}{l}\text { Tr: In case you forget ... we gonna do the next part, } \\
\text { which is about your ... Quick writing. } \\
\text { SS: (Listening attentively) }\end{array}$ \\
\hline
\end{tabular}

\subsection{Modelling}

Mediating through scaffolding can be effected through the modelling stage of the genre teaching-learning cycle [13] where the teacher provides a model text type and analyzes the text in terms of text structure and its linguistics features [22]. This was seen in Teacher A indicating to students that sample texts would be shown to them later in the lesson to model how to write by showing the students the text structure of a parallel story and how to construct sentences to write the narrative according to the text structure (see Modelling Examples 1A, 2A and 1B in Table 4).

Table 4. Modelling.

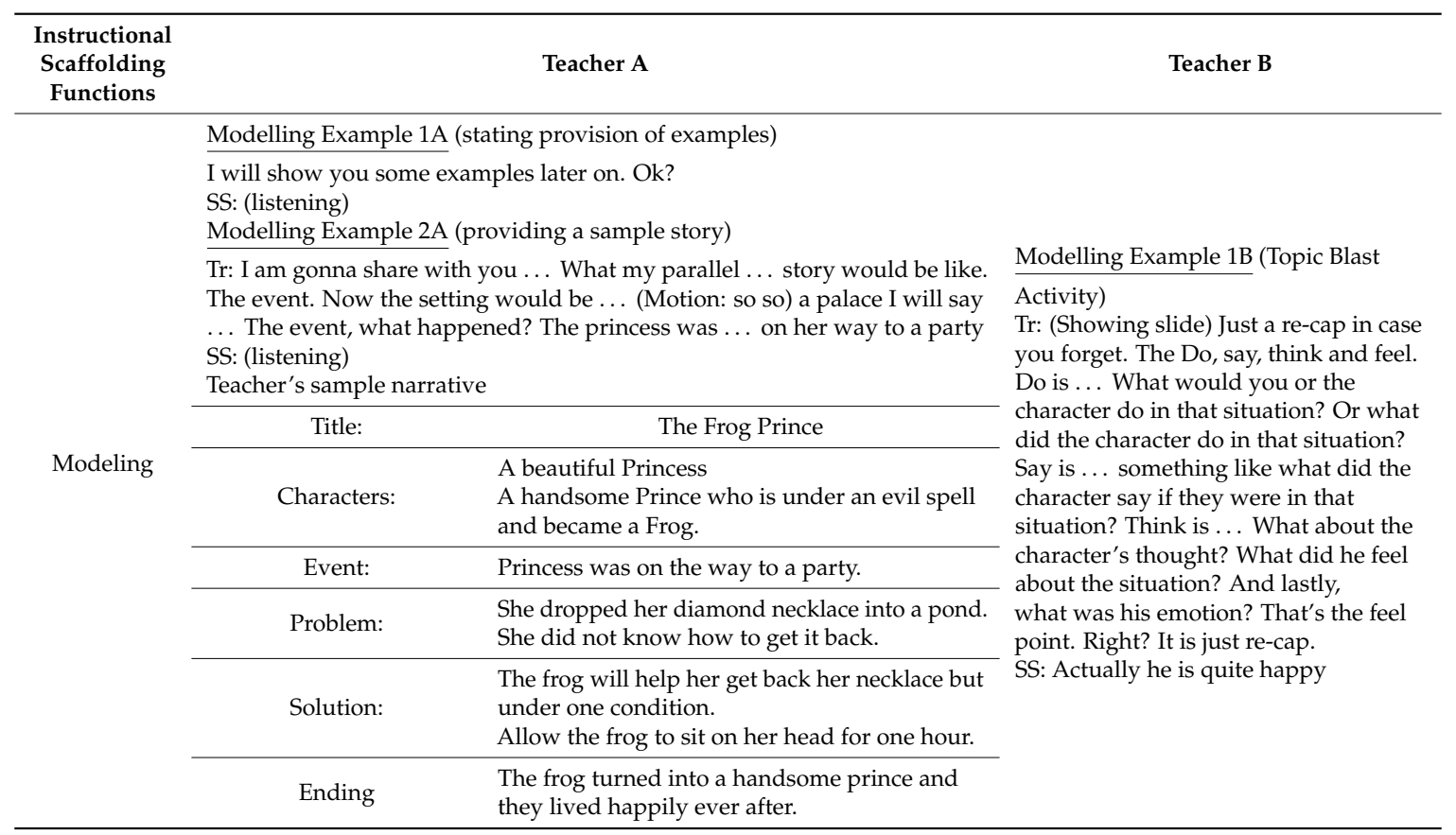


For the instructional scaffolding function of modelling, besides students being given examples of the completed writing task, the teacher models "appropriate language use for the performance of specific academic functions" [1] (p. 170). Teacher B modelled the thinking process involved in constructing sentences to fit the requirement for the narrative to be about a pleasant surprise. Teacher $B$ asked a lot of questions to model how students needed to ask themselves questions while recalling what they had learnt the previous lesson - to enable students to be cognitively engaged in planning how to write (see Modelling Example 1B). Both teachers made visible either text structure or self-talk for writing a story to the students [2].

\subsection{Bridging: Activating Students' Prior Knowledge}

Consistent with the findings of Walqui's [1] and Simeon's [2] studies, the two teachers provided instructional scaffolding by using bridging approaches to help learners learn the concept of planning in writing mainly by activating students' prior knowledge. The teacher linked new contexts and understandings to what students already knew about writing [8] through recapitulating what was taught in the previous lessons (see Bridging Examples 1A, 2A, 1B, 2B and 3B in Table 5).

Table 5. Bridging.

\begin{tabular}{|c|c|c|}
\hline $\begin{array}{l}\text { Instructional } \\
\text { Scaffolding } \\
\text { Functions }\end{array}$ & Teacher A & Teacher B \\
\hline \multirow{6}{*}{ Bridging } & \multirow{4}{*}{$\begin{array}{l}\text { Bridging Example } 1 \mathrm{~A} \\
\text { Tr: Just a quick recap for what we just ... } \\
\text { what we did ... on our last lesson ... the } \\
\text { first thing we did was introducing the } \\
\text { fractured fairy tales to you, right? } \\
\text { (Teacher recap story map and parallel story) } \\
\text { SS: Yes (choral) } \\
\text { Bridging Example 2A }\end{array}$} & Bridging Example 1B \\
\hline & & Tr: We gonna do a bit of a revision for our \\
\hline & & $\begin{array}{l}\text { composition } \\
\text { SS: (Listening attentively) } \\
\text { Bridging Example 2B }\end{array}$ \\
\hline & & $\begin{array}{l}\text { Tr: ... before that let's do a very simple recap. So do } \\
\text { you remember what did we do in out last writing? } \\
\text { What was the topic? What strategy did we use? } \\
\text { What was the topic about? }\end{array}$ \\
\hline & \multirow{2}{*}{$\begin{array}{l}\text { Tr: ... based on the last exercise we did as a } \\
\text { class. Prince Zak and The Wise Frog, do } \\
\text { you still remember? } \\
\text { SS: (Listening) }\end{array}$} & $\begin{array}{l}\text { SS: (Listening attentively) } \\
\text { Bridging Example 3B (Topic Blast Activity) }\end{array}$ \\
\hline & & $\begin{array}{l}\text { Tr: (Showing slide: Just a re-cap) In case you forget. } \\
\text { The Do, say, think and feel. } \\
\text { SS: (Listening attentively) }\end{array}$ \\
\hline
\end{tabular}

\subsection{Contextualising}

To make academic language more accessible and engaging for students, both teachers used analogies. Teacher A guided the students to understand the concept of main idea by using analogies and acting out to prompt students during group conferencing (see Contextualising Examples $1 \mathrm{~A}$ and 2A in Table 6) while Teacher B gave examples from real life scenarios to explain the concepts of tangible and intangible experiences (see Contextualising Example 1B below).

\subsection{Schema Building}

Activating students' schema and weaving new information into pre-existing structures of meaning will enable students to accept new connections and organize knowledge and understanding [1]. Both teachers did so by constant reference to what students had learnt about writing from their previous lessons through signaling words such as 'a quick recap', 'remember', 'you did it before right?' (see Schema Building Examples 1A, 1B and 2B in Table 7). This was to help students think about their pre-existing understanding of how to write so as to enable new applications such as coming up with their own story maps for Teacher A and using the "Do, Say, Think and Feel" sentences for Teacher B. Schema activation was done to build knowledge about the narrative genre to enable application in writing. 
Table 6. Contextualising.

\begin{tabular}{|c|c|c|}
\hline $\begin{array}{l}\text { Instructional } \\
\text { Scaffolding } \\
\text { Functions }\end{array}$ & Teacher A & Teacher B \\
\hline \multirow{14}{*}{ Contextualising } & Contextualising Example 1A & \multirow{14}{*}{$\begin{array}{l}\text { Contextualising Example 1B } \\
\text { Tr: If you look at the next slide (showing the slide: } \\
\text { tangible VS intangible), the things that surprise you ... } \\
\text { either tangible or "intangible. So what is this? What is } \\
\text { tangible and intangible? So tangible is something that is } \\
\text { physical ... that you can touch. For example, a birthday } \\
\text { gift. I got a gift, I got an X-box, I got a PSP. } \\
\text { SS: Something that makes feel good (a few SS) } \\
\text { S8: Give four people money } \\
\text { Tr: Oh, you give four people money. That makes you ... } \\
\text { happy, right? ... What do you think is another example } \\
\text { of intangible surprise? } \\
\text { S25: Someone shout [at] you with surprise that you are } \\
\text { the best person in the world. } \\
\text { Tr: He didn't really give anything physical, but he says } \\
\text { "Oh, you are actually the best person in the world." }\end{array}$} \\
\hline & \multirow{9}{*}{$\begin{array}{l}\text { Tr: What is the main idea here? Something } \\
\text { actually? (Motion: grabbing \& dropping) } \\
\text { something? } \\
\text { SS: I don't know. } \\
\text { Tr: (Motion: dropping) Something? (motion: } \\
\text { dropping eraser) } \\
\text { SS: Fell. } \\
\text { Tr: The main idea is something fell ... and ... } \\
\text { the person (motion: holding something) who } \\
\text { drops this item ... Can he or she retrieve the } \\
\text { item? } \\
\text { SS1,3,4: No (shaking head to express "no") } \\
\text { Contextualising Example 2A }\end{array}$} & \\
\hline & & \\
\hline & & \\
\hline & & \\
\hline & & \\
\hline & & \\
\hline & & \\
\hline & & \\
\hline & & \\
\hline & Tr: The idea is about ... (picking up the eraser) & \\
\hline & someone $\ldots$ either the prince or the princess & \\
\hline & $\begin{array}{l}\ldots \text { what is it? (dropping the eraser) What } \\
\text { happened? (dropping the highlighter) }\end{array}$ & \\
\hline & SS: Fell/drop & \\
\hline
\end{tabular}

Table 7. Schema Building.

\begin{tabular}{|c|c|c|}
\hline $\begin{array}{l}\text { Instructional } \\
\text { Scaffolding } \\
\text { Functions }\end{array}$ & Teacher A & Teacher B \\
\hline \multirow{5}{*}{ Schema Building } & \multirow{5}{*}{$\begin{array}{l}\text { Schema Building Example 1A (Pre activity) } \\
\text { Tr: Just a quick recap for what we just ... our last } \\
\text { lesson. The first thing we did was introducing } \\
\text { the fractured fairy tales to you, right? And ah } \\
\ldots \text { what we did next was we read the original } \\
\text { version of Little Red Riding Hood and after } \\
\text { which we watched the? (Tr pausing video) } \\
\text { SS: Yes (choral) }\end{array}$} & Schema Building Example 1B \\
\hline & & $\begin{array}{l}\text { Tr: Try also to create the story with a climax. Remember } \\
\text { what is a climax? }\end{array}$ \\
\hline & & SS: Something exciting happening. \\
\hline & & $\begin{array}{l}\text { Tr: Look at the box for video one. Think about Do, Say, } \\
\text { Think and Feel sentences. } \\
\text { SS: (viewing attentively) } \\
\text { Schema Building Example 3B (Quick Writing) }\end{array}$ \\
\hline & & $\begin{array}{l}\text { Tr: (Showing slide): Just a recap ... in case you forget. } \\
\text { You just choose one of these three different scenarios, } \\
\text { and you write down a sentence for each. And at the end } \\
\text { you try to combine all these sentences into one } \\
\text { paragraph. You did it before right? So let's try it again. } \\
\text { SS: (listening) }\end{array}$ \\
\hline
\end{tabular}

\subsection{Re-Presenting Text}

In terms of asking students to transform the linguistic constructions of one genre into another genre, only Teacher A seemed to be doing that in asking students to write a parallel story (see Table 8).

Table 8. Re-presenting text.

\begin{tabular}{|c|c|c|}
\hline $\begin{array}{c}\text { Instructional } \\
\text { Scaffolding Functions }\end{array}$ & Teacher A & Teacher B \\
\hline \multirow{3}{*}{ Re-presenting text } & Re-presenting Text Example 1A (Pre activity) & \\
\hline & $\begin{array}{l}\text { Tr: We then moved on to construct a very simple parallel story by } \\
\text { applying ... What we have learned is the ... ? (pointing to the board) } \\
\text { STAR. What is S again? } \\
\text { SS: Substitute (Choral) } \\
\text { Re-presenting Text Example 2A (Group conference) }\end{array}$ & \\
\hline & $\begin{array}{l}\text { Tr: The story we did? (pointing to the paper) this one? Do you } \\
\text { remember the story? We changed a bit, right? } \\
\text { SS: Yes } \\
\text { Tr: Instead of the palace gardens, we changed to ... Vista? Point. Ah, } \\
\text { Vista park. } \\
\text { SS: Park. }\end{array}$ & \\
\hline
\end{tabular}




\subsection{Developing Metacognition}

Teacher A's development of students' metacognitive knowledge occurred during the students' group discussion to plan a group narrative in terms of Raphael et al.'s [6] types of metacognitive knowledge, (1) declarative knowledge when the students were reminded to focus on task goals and steps for writing in the teacher asking: 'What are the problems? Was there a condition' (see Example 2A in Table 9); (2) procedural knowledge by prompting the students on how strategies were to be implemented or deciding which strategy to use when composing: 'Your group, what are the ideas in your group? The characters? Who are the characters, what is the item that was dropped? Then what happened in the end?' (see Example 3A) and (3) conditional knowledge-the conditions to use a particular strategy or knowing when and why to use strategies during the writing process when the teacher told the students to 'write ... brainstorm ... the idea first ... scribe your ideas' (see Example 1A) as the initial step in planning to write.

Table 9. Developing metacognition.

\begin{tabular}{|c|c|c|}
\hline $\begin{array}{l}\text { Instructional } \\
\text { Scaffolding } \\
\text { Functions }\end{array}$ & Teacher A & Teacher B \\
\hline \multirow{5}{*}{$\begin{array}{l}\text { Developing } \\
\text { Metacognition }\end{array}$} & Metacognition Example 1A (Group conference-Joint & Metacognition Example 1B \\
\hline & \multirow{4}{*}{$\begin{array}{l}\text { construction) } \\
\text { Tr: You are ... to construct ... a story map on your } \\
\text { own ... parallel to what you have just read. Discuss as } \\
\text { a group. You may want to write down your ideas } \\
\text { alright? (pointing to the story elements that they did } \\
\text { on the board) the characters, the setting, the event, } \\
\text { problem, solution and ending. Write ... brainstorm ... } \\
\text { the idea first ... scribe your ideas. } \\
\text { SS: Yes. } \\
\text { Metacognition Example 2A (Group conference) } \\
\text { Tr: What are the problems? Was there a condition? } \\
\text { SS: No. } \\
\text { Metacognition Example } 3 \text { A (Group conference) } \\
\text { Tr: Your group, what are the ideas in your group? The } \\
\text { characters? Who are the characters, what was the item } \\
\text { that was dropped? Then what happened in the end? } \\
\text { SS: Title? }\end{array}$} & $\begin{array}{l}\text { Tr: Before that, let's do a very simple recap. So do } \\
\text { you remember what did we do in our last writing? } \\
\text { What was the topic? What strategy did we use? } \\
\text { SS: (listening attentively) } \\
\text { Metacognition Example 2B (Topic Blast Activity) }\end{array}$ \\
\hline & & $\begin{array}{l}\text { Tr: (to S28) Do you manage to write a complete } \\
\text { sentence? Who is he? "He played with Cristiano } \\
\text { Ronaldo" he refers to? } \\
\text { SS: the boy } \\
\text { Metacognition Example 3B (Quick Writing) }\end{array}$ \\
\hline & & $\begin{array}{l}\text { (Showing slide: Just a recap) in case you forget. } \\
\text { The quick writing. You can just write the gist of your } \\
\text { story. So when you translate it to your composition, }\end{array}$ \\
\hline & & $\begin{array}{l}\text { you may ... you must include "introduction" you } \\
\text { just also have your conclusion. This is just the gist of } \\
\text { your story. The main part of your story. } \\
\text { SS: (listening) }\end{array}$ \\
\hline
\end{tabular}

Teacher B developed the students' metacognitive knowledge throughout the lesson rather than during group work: (1) Declarative knowledge when the students were asked to recall the strategy they were taught to use in writing: 'So do you remember what did ... we do in out last writing? What was the topic? What strategy did we use?' (See Example 1B); (2) procedural knowledge by prompting the students on the strategy used when they were composing: '(to S28) do you manage to write a complete sentence?' (see Example 2B) and (3) conditional knowledge-the conditions to use a particular strategy when the teacher reminded the students that for quick writing 'You can just write the gist of your story. So when you translate it to your composition, you may ... you must include "introduction" you just also have your conclusion' (see Example 3B).

\section{Discussion}

In implementing the socio-cognitive approach to writing, the teachers in the present study mediated learning how to write through these instructional scaffolding functions to varying extents to help their students reach a higher state of independence when planning and writing a narrative: explicit outcomes and expectations, modelling, bridging, contextualizing, schema building, re-presenting text and developing metacognition [1,3]. While Simeon [2] has looked at the teacher's discourse in teaching writing chiefly in terms of: (1) Bridging: "sharing personal experiences" and "activating students' prior knowledge" and (2) modeling, the present study has looked at all of Walqui's [1] instructional 
scaffolding functions besides the inclusion of Hyland's [3] Contextualising and Stating outcomes and expectations.

The study has demonstrated how in line with one of Hyland's [3] principles, as part of instructional scaffolding, $95 \%$ of the teachers stated explicitly the lesson outcomes/objectives and their expectations at the beginning and throughout the lesson to raise students' awareness of what was being studied, why it was being studied and what would be expected of them [3]. This is because goals can influence how learners interpret and use scaffolds [19] and teachers need to clarify learning intentions in teaching $[15,24]$.

Given that the teachers were teaching using the socio-cognitive approach involving the modelling stage of the genre teaching-learning cycle [13], teachers provided model narrative text type and analyzed its linguistics features [22]. For instance, in practice, the two teachers modelled by making visible the text structure for a parallel story construction or how to construct sentences and Teacher B even modelled the thinking process involved in constructing sentences to stimulate students' inner language for thinking for text construction and monitoring [22].

Bridging for the concept of planning in writing was done mainly by activating students' prior knowledge [21]. Schema activation was in the teachers' constant reference to what students should have learnt about writing from their previous lessons to build on knowledge about the narrative genre and to enable application in writing. This echoes what Belland [16] has advocated in terms of teachers tapping into students' existing knowledge, extending the knowledge by showing students how to use the knowledge in new ways or for more complex tasks and pointing out the critical factors students should attend to.

The teachers' development of metacognitive knowledge [25] was in terms of Raphael et al.'s [6] three types of metacognitive knowledge: declarative, procedural and conditional knowledge. In terms of contextualizing, the teachers used either analogies or examples from real life to make academic language more accessible and engaging for students. In terms of re-presenting text, only Teacher $\mathrm{A}$ could be said to be doing that in this study.

\section{Conclusions}

The present study has investigated how teachers helped elementary students mediate learning how to write narratives in a socio-cognitive approach through these instructional scaffolding functions: explicit outcomes and expectations, modelling, bridging, contextualizing, schema building, re-presenting text and developing metacognition [1,3]. While this study echoed the findings of Simeon [2] in terms of modelling, bridging and contextualizing, the study has extended Simeon's [2] study by investigating all of Walqui's [1] instructional scaffolding functions by looking at 21 lessons for an overview of usage and specific examples drawn from two teachers' classroom talks. The specific examples from these teachers provides qualitative descriptive data in the domain of pedagogical approaches in writing for elementary students.

Though the teachers were shown to utilize most of the instructional scaffolding functions, for future research, more studies need to be conducted to find out which instructional scaffolding functions will be predominantly used and for what kinds of writing genres in addition to how these functions will vary with different groups of teachers and students. Still, the adapted instructional scaffolding functions provide a means for teachers to mediate the learning of writing and the present study suggests that both teachers and trainers in teacher education courses might usefully pay more attention to developing teachers' understandings of the role of mediating learning to write through instructional scaffolding functions $[1,3,26]$.

Author Contributions: C.H. Ng and Y.L. Cheung conceived and designed the data collection and analysis; C.H. Ng analyzed the data and wrote the first draft of the paper; Y.L. Cheung provided support for the data collection and analysis; all authors contributed to the final manuscript.

Acknowledgments: We would like to thank teachers and students who took part in this study, and OER 07/15 for funding this project. 
Conflicts of Interest: The authors declare no conflict of interest.

\section{References}

1. Walqui, A. Scaffolding instruction for English language learners: A conceptual framework. Int. J. Biling. Educ. Biling. 2006, 9, 159-180. [CrossRef]

2. Simeon, J. Scaffolding learner writing strategies in an ESL secondary class in the Seychelles: A Sociocultural perspective. N. Z. Stud. Appl. Linguist. 2015, 21, 21-38.

3. Hyland, K. Genre pedagogy: Language, literacy and L2 writing instruction. J. Second Lang. Writ. 2007, 16, 148-164. [CrossRef]

4. Martin, J.R. English Text: System and Structure; John Benjamins: Amsterdam, The Netherlands, 1992.

5. Flower, L.S.; Hayes, J.R. The pregnant pause: An inquiry into the nature of planning. Res. Teach. Engl. 1981, 15, 229-243.

6. Raphael, T.; Englert, C.; Kirschner, B. Students' metacognitive knowledge about writing. Res. Teach. Engl. 1989, 23, 343-379.

7. Brooks, L.; Swain, M. Languaging in Collaborative Writing: Creation of and Response to Expertise. In Multiple Perspectives on Interaction in SLA; Mackey, A., Polio, C., Eds.; Lawrence Erlbaum: Mahwah, NJ, USA, 2009; pp. 58-89.

8. Cotteral, S.; Cohen, R. Scaffolding for second language writers: Producing an academic essay. ELT J. 2003, 57, 158-166. [CrossRef]

9. Riazi, M.; Rezaii, M. Teacher- and Peer-Scaffolding Behaviors: Effects on EFL Students' Writing Improvement. In Proceedings of the 12th National Conference for Community Languages and ESOL, Dunedin, New Zealand, 1-4 October 2011; pp. 55-63. Available online: http:/ / www.tesolanz.org.nz/ (accessed on 31 January 2018).

10. Baker, S.; Gersten, R.; Scanlon, D. Procedural facilitators and cognitive strategies: Tools for unraveling the mysteries of comprehension and the writing process and for providing meaningful access to the general education curriculum. Learn. Disabil. Res. Pract. 2002, 17, 65-77. [CrossRef]

11. Huxford, L. Developing an understanding of the pedagogy of writing in the middle years (age 8-11). Aust. J. Lang. Lit. 2004, 27, 234-244.

12. Vygotsky, L.S. Mind in Society: The Development of Higher Psychological Processes; Harvard University Press: Cambridge, MA, USA, 1978.

13. Hyland, K. Genre-based pedagogies: A social response to process. J. Second Lang. Writ. 2003, 12, 17-29. [CrossRef]

14. Halliday, M.A.K. An Introduction to Functional Grammar, 2nd ed.; Edward Arnold: London, UK, 1994.

15. Wood, D.; Bruner, J.; Ross, G. The role of tutoring in problem solving. J. Child Psychol. Child Psychiatry 1976, 17, 89-100. [CrossRef]

16. Belland, B.R. Instructional Scaffolding in STEM Education: Strategies and Efficacy Evidence; Springer: Cham, Switzerland, 2017.

17. Reiser, B.J. Scaffolding complex learning: The mechanisms of structuring and problematizing student work. J. Learn. Sci. 2004, 13, 273-304. [CrossRef]

18. Belland, B.R.; Kim, C.; Hannafin, M. A framework for designing scaffolds that improve motivation and cognition. Educ. Psychol. 2013, 48, 243-270. [CrossRef] [PubMed]

19. Belland, B.R.; Glazewski, K.D.; Richardson, J.C. A scaffolding framework to support the construction of evidence-based arguments among middle school students. Educ. Technol. Res. Dev. 2008, 56, 401-422. [CrossRef]

20. Glaser, B.G.; Strauss, A.L. The Discovery of Grounded Theory: Strategies for Qualitative Research; Aldine: Chicago, IL, USA, 1967.

21. Gibbons, P. English Learners Academic Literacy and Thinking: Learning in the Challenge Zone; Heinemann: Portsmouth, UK, 2009.

22. Derewianka, B.; Jones, P. Teaching Language in Context; Oxford University Press: Melbourne, Australia, 2013.

23. Viriya, C.; Wasanasomsithi, P. The Effect of the Genre Awareness Approach on Development of Writing Ability. Int. Forum Teach. Stud. 2017, 13, 11-22.

24. Hattie, J.A.C. Visible Learnings: A Synthesis of 800+ Meta-Analysis Relating to Achievement; Routledge: Oxford, UK, 2009. 
25. Paris, S.G.; Winograd, P. How metacognition can promote academic learning and instruction. In Dimensions of Thinking and Cognitive Instruction; Jones, B.F., Idol, L., Eds.; Lawrence Erlbaum: Hillsdale, NJ, USA, 1990; pp. 15-51.

26. Gibbons, P. Mediating language learning: Teacher interactions with ESL students in a content-based classroom. TESOL Q. 2003, 37, 247-273. [CrossRef] 